\title{
THERMOECONOMIC EVALUATION \& INTELLIGENT OPTIMIZATION OF SOLAR-THERMAL DRIVEN SINGLE-EFFECT LiBr-H2O ABSORPTION REFRIGERATION SYSTEM
}

\section{RAVINDRA KANNOJIYA \& RAJESH KUMAR}

Department of Mechanical Engineering, Delhi Technological University, Delhi, India

\begin{abstract}
A single effect absorption refrigeration system is analyzed which utilize solar energy to provide heat input from the viewpoint of thermodynamics and economics. The flat-plate collector is considered for study of the operation of current system which emphasize use of renewable energy sources for the system analysis and various exergy based applications in the field of sustainable energy and its management. The cost parameters for various components are also included in the computational model to check the effects of exergy losses associated with the streams of the components of the system, using Engineering Equation Solver (EES). A cost minimization method is applied to determine the economic costs of flows and products of the system by using various cost equations. The system performance evaluated to observe the effects of variables on costs and enables to suggest values of design variables that would make the overall system cost effective. An intelligent optimization technique (TLBO) is used to find optimal set of values necessary for the system in a multiobjective optimization process. These values of absorber, condenser and generator temperatures are studied to learn the behavior of the system. The exergy streams in the heat rejecting and absorbing components play a vital role in the performance of VARS. This researchaims to examine the control variables and focus on aspects of the concept of flow and quality of energy.

KEYWORDS: Absorption Refrigeration, Computational Model, Exergy, Thermoeconomic Evaluation, , Renewable Energy
\end{abstract}

Received: Jun 09, 2020; Accepted: Jun 29, 2020; Published: Aug 01, 2020; Paper Id.: IJMPERDJUN2020567

\section{INTRODUCTION}

It is reported that particular type and size of heat exchangers as well as the control variables can be assigned for a specific application [1]. The control variables such as supply steam pressure and temperature, condenser water temperature, flow rate, chilled water temperature are important in the workable design of a refrigeration system. The energy scenario suggests that the unconventional sources, providing heat input in absorption refrigeration systems are the subject of increasing interest. They can be operated by eco-friendly working fluids and at low temperature conditions. A few researchers have determined the performance as well as cost parameters relations with the system [2-3]. They have also optimized the system for cost effectiveness and utilization of energy. Work has been performed on the analysis of single-effect absorption refrigeration using direct-fired system and a part of cogeneration system [4]. There can be use of evolutionary algorithms for determination of global optimal solutions in a multi-objective optimization problem. The work of d'Accadia and de Rossi [5] and Wall [6], suggest that the optimization of thermal systems may not be feasible at times, with the help of numerical techniques due to various complicacies. In the recent times various methods have been proposed, involving cost evaluation by taking into account the second law of thermodynamics. As found in literature, there are two groups of methods: Firstly, the cost 
accounting methods that use the average costs as a basic for a rational price assessment. These include the average cost approach (AVCO), discussed by Bejan et al. [7] and Tsatsaronis and Pisa [8], and the theory of exergetic cost, discussed by Lozano and Valero [9]. Secondly, the optimization methods that employ marginal costs to minimize the costs of system products or components. These include the Thermoeconomic Functional Analysis (TFA) [10] and the Engineering Functional Analysis (EFA) [11]. The most significant advantage of all these optimization methods lies in its capacity to solve complex practical problems without using sophisticated methods of numerical analysis. In this work, the average cost approach (AVCO) is used to evaluate a heat operated single effect water/LiBrvapour absorption refrigeration (VAR) system. The method consists of a detailed exergy analysis followed by determination of average cost per unit exergy of all the internal flows and products appearing in the representation of the system. Based on these, an iterative optimization procedure is adopted aiming at minimizing the overall economic cost of product (i.e. desired cooling effect) with respect to an assigned set of design variables.

\section{ASSUMPTIONS FOR EVALUATION}

The schematic representation of a solar operated $\mathrm{LiBr}-\mathrm{H}_{2} \mathrm{O}$ single-effect vapor absorption refrigeration system is provided in Fig. 1. In the analysis of system the following assumptions are considered:

- The system is assumed to be in steady state and the solar energy distribution is uniform.

- Lithium bromide solutions in the generator and the absorber are assumed to be in equilibrium.

- Refrigerant at condenser and evaporator exit is in saturated state.

- Strong solution of refrigerant leaving the absorber and the weak solution of refrigerant leaving the generator are saturated.

- No pressure losses are considered in analysis of heat exchangers and the pipelines.

- The reference environment state for the system is water at $25^{\circ} \mathrm{C}$.

- The temperature of the solution entering the throttling valve considered to be at least $7-8^{\circ} \mathrm{C}$ above crystallization temperature.

The system uses external current of steam to drive generator and it provides chilled water in the evaporator.

\section{BRIEF DESCRIPTION OF THERMAL SYSTEM}

The proposed thermal system involves a flat plate collector for providing the energy input. The working of the system depends on temperature and pressure conditions of the components and their assembly. The renewable energy source give the heat input as required for the operation of the system. The input and output streams suggest the exergy calculations for further behavior of the thermal system. The external streams are connected to components of the absorption system as 11 \& 12 with condenser unit, $13 \& 14$ with evaporator unit, $15 \& 16$ with absorber unit and as $17 \& 18$ with collector and generator. The thermodynamic state points are represented in Fig 1 showing the outline of the system. 


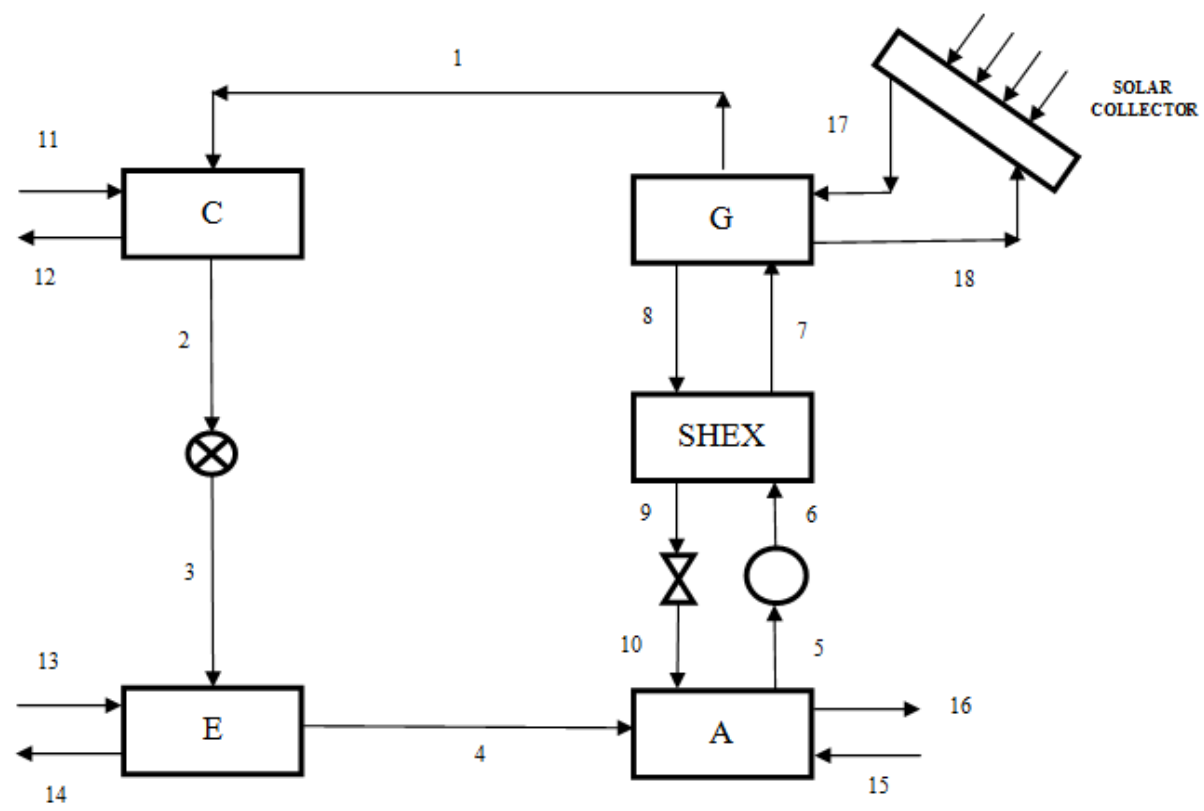

Figure 1: Single-Effect Absorption Refrigeration System with Solar Collector.

\section{METHODOLOGY}

The various state point conditions are calculated using the properties of the working fluids in EES software. The fundamental equations are used to find the exergy components of the cycle. For the multi-objective problem MATLAB programming has been done and TLBO algorithm has been applied. The wide use of this algorithm has proven to be useful for balance in cost and exergy relationship. The flow chart of the algorithm shows that the initiation and final stage should satisfy the criteria for producing optimized result.

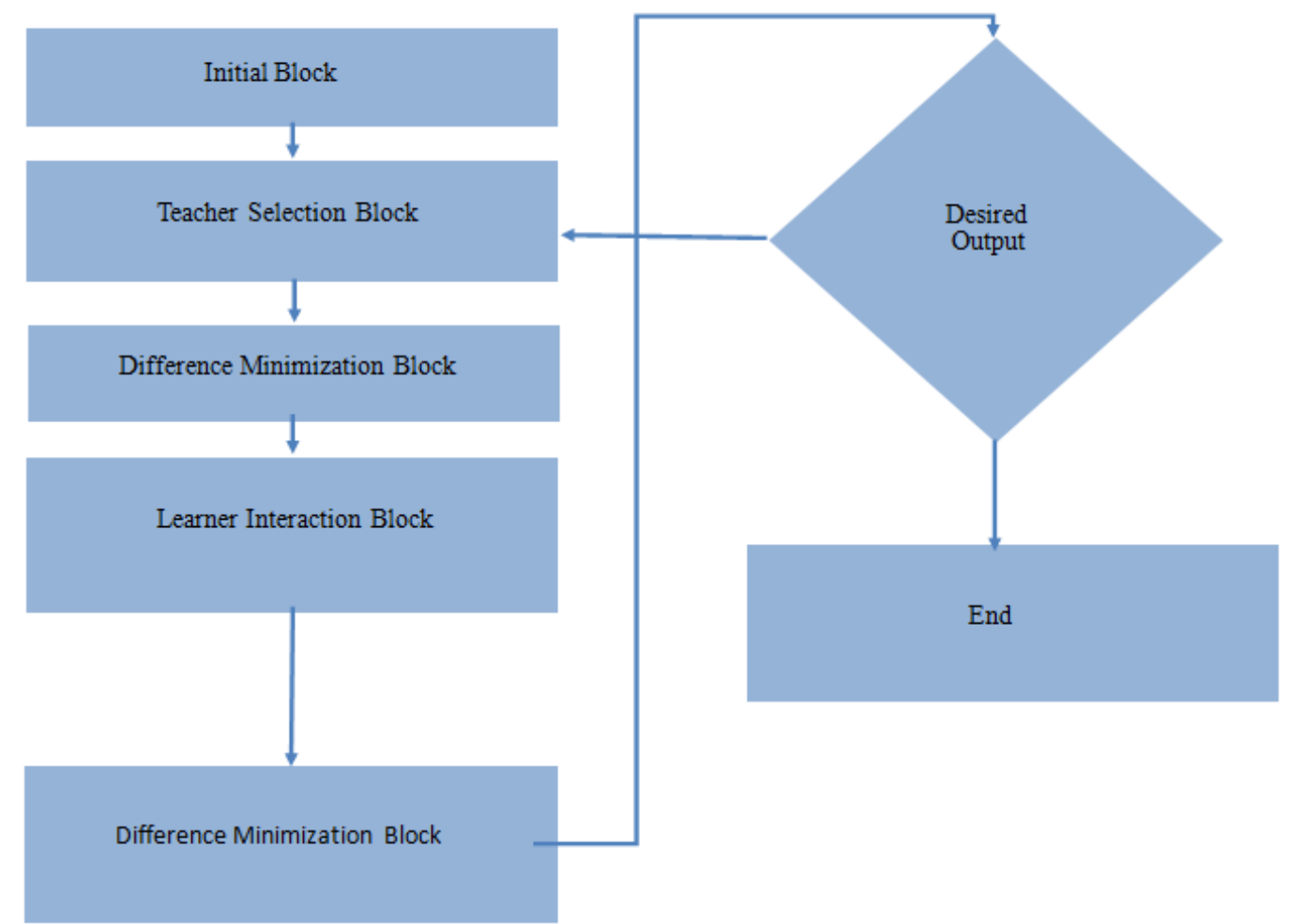

Figure 2: Flowchart of TLBO Working [12] 
Figure 2 shows the detailed process of the criteria to be fulfilled by the algorithm and then the termination of the process will be decided. With the help of simulations in EES the thermodynamic analysis has been performed and the state points have been determined to successfully obtain the input conditions for exergy calculations.

Table 1: State Points of Components through EES

\begin{tabular}{|c|c|c|c|c|c|}
\hline $\begin{array}{c}\text { State } \\
\text { Points }\end{array}$ & $\begin{array}{c}\text { Pressure } \\
(\mathbf{k P a})\end{array}$ & $\begin{array}{c}\text { Temperature } \\
(\mathbf{K})\end{array}$ & $\begin{array}{c}\text { Mass Flow Rate } \\
(\mathbf{k g} / \mathbf{s})\end{array}$ & $\begin{array}{c}\text { Concentration } \\
(\mathbf{L i B r})(\boldsymbol{\%})\end{array}$ & $\begin{array}{c}\mathbf{E} \\
(\mathbf{k W})\end{array}$ \\
\hline 1 & 5.952 & 353 & 0.042 & - & 5.193 \\
\hline 2 & 5.952 & 309 & 0.042 & - & 1.183 \\
\hline 3 & 0.872 & 278 & 0.042 & - & 0.8887 \\
\hline 4 & 0.872 & 278 & 0.042 & - & -6.249 \\
\hline 5 & 0.872 & 307 & 0.591 & 0.5468 & 14.59 \\
\hline 6 & 5.952 & 307 & 0.591 & 0.5468 & 14.59 \\
\hline 7 & 5.952 & 334.6 & 0.591 & 0.5468 & 16.91 \\
\hline 8 & 5.952 & 353 & 0.549 & 0.5967 & 34.48 \\
\hline 9 & 5.952 & 323.6 & 0.549 & 0.5967 & 30.8 \\
\hline 10 & 0.872 & 316.9 & 0.549 & 0.5967 & 37.25 \\
\hline $17-18$ & 101.3 & 373 & 0.062 & - & 30.24 \\
\hline $13-14$ & 101.3 & $285-293$ & 2.981 & - & 3.114 \\
\hline $11-12$ & 101.3 & $300-305$ & 5.041 & - & 1.566 \\
\hline $15-16$ & 101.3 & $300-305$ & 6.352 & - & 1.981 \\
\hline
\end{tabular}

\section{RESULTS \& DISCUSSIONS}

The optimization of the system has been performed by MATLAB. The multi-objective nature of the problem provided the exergy loss and cost relation. On the basis of the system conditions the algorithm works for the optimization and also time constraint provides the variation of COP. Table 2 provides the exergetic efficiency and exergy destruction of the components. Similarly variation of COP can be discussed with respect to time. Figure 3 shows the variation of the system behaviour

Table 2: Exergy Analysis for Operating Conditions of VARS

\begin{tabular}{|l|c|c|c|c|c|c|c|}
\hline \multicolumn{1}{|c|}{ Component } & $\begin{array}{c}\text { Fuel } \\
\text { Exergy } \\
(\mathbf{k W})\end{array}$ & $\begin{array}{c}\text { Product } \\
\text { Exergy } \\
(\mathbf{k W})\end{array}$ & $\begin{array}{c}\text { Exergy } \\
\text { Destruction } \\
\mathbf{( k W )}\end{array}$ & $\begin{array}{c}\text { Exergy } \\
\text { Loss } \\
(\mathbf{k W})\end{array}$ & $\begin{array}{c}\text { Exergy } \\
\text { Loss Ratio } \\
(\boldsymbol{\%})\end{array}$ & $\begin{array}{c}\text { Exergy } \\
\text { Destruction } \\
\text { Ratio }(\boldsymbol{\%})\end{array}$ & $\begin{array}{c}\text { Exergetic } \\
\text { Efficiency } \\
(\%)\end{array}$ \\
\hline Generator & 30.24 & 22.763 & 7.477 & 0.000 & 0.000 & 24.723 & 75.274 \\
\hline $\begin{array}{l}\text { Evaporator } \\
\text { Assembly parts } \\
\text { (Absorber and } \\
\text { Condenser) }\end{array}$ & 21.403 & 3.114 & 14.742 & 3.547 & 11.728 & 48.745 & 14.549 \\
\hline Pump & & & & & & & \\
\hline Heat Exchanger & 3.68 & 2.32 & 1.36 & 0.000 & 0.000 & 4.496 & 63.043 \\
\hline Entire System & 30.243 & 3.114 & 23.58 & 3.547 & 11.728 & 77.967 & 10.296 \\
\hline
\end{tabular}




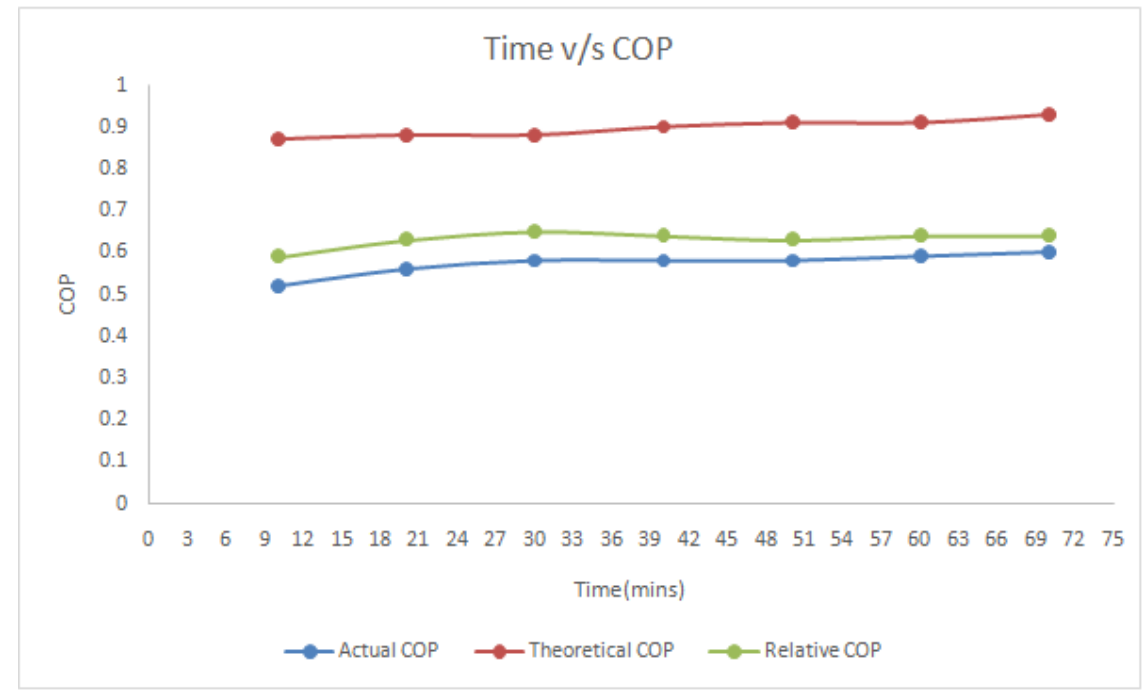

Figure 3: Variation of COP in Real Time.

\section{CONCLUSIONS}

The results obtained can be compared with various refrigerant configurations combined together for running the system. On the basis of the computations performed, one would be able to propose an application of other unconventional sources of power as a source of energy for the generator to run. In that case we can use heat from the source and focus it on running water in a tube that would be heated till boiling point or the temperature required after calculations of losses of friction and heat loss during flow to the generator. If sufficient conduction is achieved the water from collecting medium can be used in the process of evaporative water cooled condenser system before going back to the cycle. The cost of manufacturing the setup is significantly high but can be reduced if produced in bulk for smaller applications.

\section{REFERENCES}

1. Aphornratana S, Eames IW. Thermodynamic analysis of absorption refrigeration cycles using the second law of thermodynamics method. International Journal of Refrigeration 1995; 18(4):244-52.

2. Misra R.D., Sahoo P.K., Sahoo S., Gupta A., Thermoeconomic optimization of a single effect water/LiBr

3. vapour absorption refrigeration system, International Journal of Refrigeration 26 (2003) 158-169

4. I. Pilatowsky, W. Rivera, R.J. Romero, Thermodynamic analysis of monomethylamine-water solutions in a single-stage solar absorption refrigeration cycle at low generator temperatures, Solar Energy Materials \& Solar Cells 70 (2001) 287-300

5. HaiQuanSun ,ZhenYuan Xu, HongBing Wang, RuZhu Wang, A solar/gasfired absorption system for cooling and heating in a commercial building, International Conference on Solar Heating and Cooling for Buildings and Industry, SHC 2014, Energy Procedia 70 ( 2015 ) $518-528$

6. Malhotra, Sonam, Neetu Jha, and Krutika Desai. "A super ficialsynthesis of seleniumnanospheres using wet chemical approach." Int J NanotechnolAppl 3 (2014): 7-14.

7. D'Accadia MD, de Rossi F. Thermoeconomic optimization of a refrigeration plant. International Journal of Refrigeration 1998;21(1):42-54.

8. Wall G. Optimization of refrigeration machinery. International Journal Refrigeration 1991;14:336-40. 
9. Singh, Sushil Kumar, et al. "Analytical Study of a Solar Absorption Refrigeration System. "International Journal of Mechanical and Production Engineering Research and Development (IJMPERD) 4. 5, Oct 2014, 27-34

10. Bejan A, Tsatsaronis G, Moran M. Thermal design and optimization. New York: John Wiley and Sons Inc; 1996.

11. Tsatsaronis G, Javier P. xergoeconomics evaluation and optimization of energy systems-application to the CGAM problem. Energy 1994;19(3):287-321.

12. Lozano MA, Valero A. Theory of the exergetic cost. Energy 1993;18(9):939-60.

13. Mansour, T. A., Salameh. Sawalha, and Nesreen. Salem. "A Mathematical Model for Solar Assisted Automobile A/C Based on Absorption Refrigeration System." International Journal of Mechanical Engineering (IJME) 2.4 (2013): 75-86.

14. Frangopoulos CA. Application of the thermoeconomic functional approach to the CGAM problem. Energy 1994; 19(3):32342.

15. Kalbande, S. R., SnehaDeshmukh, and V. P. Khambalkar. "Evaluation study of solar water desalination system for saline track area of Vidharbaregion." Int. J. Appl. Nat. Sci.(IJANS) 6.1 (2017): 55-64.

16. VonSpakovsky MR. Application of engineering functional analysis to the analysis and optimization of the CGAM problem. Energy 1994;19(3):343-64.

17. Ravindra Kannojiya, Mohnish Dulwani, Kartikey Sharma, 2018, Proposed Algorithm (P. E. A) for Optimization, 8th International Conference on Cloud Computing, Data Science \& Engineering, 2018, 849-852. 